\title{
Effect of Hypoxemia on Fetal Hemoglobin Synthesis during Late Gestation
}

\author{
HARRY BARD, JEAN-CLAUDE FOURON, JANIE PROSMANNE, AND JACYNTHE GAGNON \\ Neonatology and Cardiology Services, Department of Pediatrics, University of Montreal and Pediatric Research \\ Centre, St. Justine's Hospilal, Montreal, Quebec H3T IC5, Canada
}

\begin{abstract}
This study was carried out to investigate the effect of fetal hypoxemia, as a result of acute intermittent maternal hypoxia, on the switchover from fetal to adult type $\mathrm{Hb}$ as well as $\mathrm{Hb}$ oxygen affinity and 2,3-diphosphoglycerate levels in the near-term fetus. These experiments were carried out using 10 fetal lambs with gestational ages ranging from 132 to $140 \mathrm{~d}$. After the installation of appropriate fetal catheters, five of the ewes were exposed to an air mixture containing $10 \% \mathrm{O}_{2}$ for $90 \mathrm{~min} / \mathrm{d}$ for 4 consecutive d. Blood samples were withdrawn before the beginning of the hypoxic experiments and between the 5 th and 6th $d$ after the first episode of hypoxia. These samples were for the determination of 2,3-diphosphoglycerate concentration, arterial $\mathrm{O}_{2}$ pressure at which $\mathrm{Hb}$ is $50 \%$ saturated, and $\mathrm{Hb}$ type synthesis. Blood gases were monitored during each hypoxic episode. During the hypoxia, fetal arterial $\mathrm{O}_{2}$ pressure decreased from $2.43 \pm 0.36 \mathrm{kPa}(18.2$ $\pm 2.7 \mathrm{~mm} \mathrm{Hg})$ to $1.57 \pm 0.17 \mathrm{kPa}(11.8 \pm 1.3 \mathrm{~mm} \mathrm{Hg})$. These values returned to their initial levels after cessation of the maternal hypoxia. Five control animals of the same gestational age were also followed. During the interval of the study, a decrease of fetal $\mathrm{Hb}$ synthesis was noted (71.7 \pm 12.1 to $57.4 \pm 10.2 \%, p<0.001$ ) in the control group. However, the level of fetal $\mathrm{Hb}$ synthesis did not significantly change in the hypoxic group $(85.1 \pm 11.1$ versus $80.6 \pm 18.9 \%$ ). At the end of the study, the hypoxic group had higher levels of fetal $\mathrm{Hb}$ synthesis when compared with the control group $(80.6 \pm 18.9$ versus $57.4 \pm 10.2 \%$, $p<0.05$ ). The 2,3-diphosphoglycerate concentrations as well as the values of arterial $\mathrm{O}_{2}$ pressure at which $\mathrm{Hb}$ was $50 \%$ saturated remained within normal limits. The data obtained in this study show that intermittent episodes of fetal hypoxemia cause an increase in the level of fetal $\mathbf{~} \mathbf{b b}$ synthesis in relation to gestational age. (Pediatr Res 31: 483-485, 1992)
\end{abstract}

\section{Abbreviations}

HbF, fetal hemoglobin

2,3-DPG, 2,3-diphosphoglycerate

$\mathrm{P}_{50}$, arterial $\mathrm{O}_{2}$ pressure at which hemoglobin is $50 \%$ saturated

Previous studies have described an increase in $\mathrm{HbF}$ in newborns born to hypoxemic (1), diabetic (2), and toxemic mothers (3). In a more recent report, it was also shown that fetal hyper-

Received September 25, 1991: accepted December 16, 1991.

Correspondence: Dr. Harry Bard, Research Center, St. Justine's Hospital, 3175 Cóte Ste-Catherine. Montreal, Quebec H3T 1C5, Canada.

Supported by Grant MA 8118 from the Medical Research Council of Canada as well as internal funds from the Faculty of Medicine. University of Montreal (CAFIR and FIRFM). glycemia causing hypoxemia resulted in an increase in $\mathrm{HbF}$ synthesis in the fetal lamb (4). Fetal hypoxemia appears to be the stimulus for an increase in HbF described in the newborn infant; however, a direct relationship between in utero hypoxemia and increased HbF synthesis has not been established.

The fetal lamb is an interesting experimental model to evaluate the effects of hypoxemia on the physiologic properties of the fetal erythrocyte. During the perinatal period, the switchover from fetal to adult $\mathrm{Hb}$ synthesis that occurs in these animals, although more rapid, is similar to that observed in humans (5), and, as in humans, the ultimate determination of the configuration of the $\mathrm{Hb}$ oxygen dissociation curve is dependent upon the type of $\mathrm{Hb}$ in the red cell and the concentration 2,3-DPG (5). Fetal lamb erythrocytes have the capacity to rapidly increase their 2,3-DPG after birth, thus lowering their oxygen affinity (6). If the fetal red cell had a similar 2,3-DPG response to hypoxemia during in utero life, it would be detrimental to the fetus by hindering adequate transfer of oxygen from mother to fetus.

A study was therefore planned to determine the effect of intermittent periods of acute hypoxemia on the relative rates of fetal and adult $\mathrm{Hb}$ synthesis as well as 2,3-DPG concentrations and the position of the $\mathrm{Hb}$ oxygen dissociation curve. The experiments were planned to be carried out at a time in gestation when the rapid switchover from fetal to adult $\mathrm{Hb}$ synthesis occurs.

\section{MATERIALS AND METHODS}

Studies were performed on 10 time-mated pregnant ewes. They were prepared between 126 and $135 \mathrm{~d}$ of gestation as previously described (4). Two polyethylene catheters were introduced in the fetal neck, one in the carotid artery and the other in the jugular vein. The catheters were passed through an s.c. canal and exteriorized on the maternal flank. During the first $48 \mathrm{~h}$ after surgery, antibiotics $(500 \mathrm{mg}$ ampicillin i.v. and $500 \mathrm{mg}$ streptomycin intramuscularly) were administered prophylactically. Five animal preparations were used for the hypoxia experiment, and five were monitored in ambient air and served as controls (These animals were to be used for other experiments only after the control period was complete.). The arterial fetal blood gas and $\mathrm{pH}$ values were measured with a blood-gas analyzer, model ABL30 (Radiometer, Copenhagen, Denmark). The $P_{50}$ was determined by tonometry, and the 2,3-DPG levels were determined by the enzymatic method as described previously (7).

Experimental protocol. On the 5 th postoperative day, fetal blood samples were drawn for the determination of the blood gases and the $\mathrm{P}_{50}$, as well as for 2,3-DPG concentrations and $\mathrm{Hb}$ type synthesis. If the blood gases were within normal range $\left(\mathrm{PO}_{2}\right.$ $\left.=2.4 \pm 0.5 \mathrm{kPa}, \mathrm{pH}=7.36 \pm 0.05, \mathrm{PCO}_{2}=5.0 \pm 0.7 \mathrm{kPa}\right)$, fetal hypoxemia was then created in the study group by having the ewe breathe an air mixture containing $10 \% \mathrm{O}_{2}$ and $3 \% \mathrm{CO}_{2}$. The procedure lasted $90 \mathrm{~min}$, and arterial blood was sampled at 15 min intervals to monitor the blood gases. At the end of the hypoxia, the animal was allowed to recover for $30 \mathrm{~min}$, after 
which the blood gases were again controlled. This procedure was repeated once a day for 4 consecutive $d$. Between 5 and $6 \mathrm{~d}$ after the first period of hypoxia, the final state was established by a second determination of the Hb type synthesis, 2,3-DPG levels, and $P_{50}$ values. The total amount of blood withdrawn from these late-gestation fetuses for each of the experiments was $10 \mathrm{~mL}$. This was the quantity required to determine the initial values of $\mathrm{Hb}$ synthesis, $\mathrm{P}_{50}$, and 2,3-DPG at the basal state as well as to measure all the blood gases obtained during the $4 \mathrm{~d}$ of the study. The second analysis of $\mathrm{Hb}$ synthesis, $\mathrm{P}_{50}$, and 2,3-DPG was carried out at the end of the experiment.

$H b$ synthesis. The $\mathrm{Hb}$ of the sheep used in this investigation were either $\mathrm{AB}$ or $\mathrm{BB}$ type. The red cells obtained were incubated in an amino acid mixture containing ${ }^{14} \mathrm{C}$-leucine and then subjected to column chromatography on carboxymethyl cellulose, a method similar to those described previously (4). The carboxymethyl cellulose provided the separation of the individual globin chains. Finally, the radioactivity incorporated into each of the globin chains was determined by liquid scintillation counting. The percentage of radioactive $\mathrm{HbF}$ to total radioactive $\mathrm{Hb}$ was based on the ratio of $\left.\gamma / \gamma+\beta{ }^{A+B}\right)$. Pre- $\gamma$ and pre- $\alpha$ radioactivities were included in the respective $\gamma$-chain and $\alpha$-chain totals.

Data were expressed as mean $\pm \mathrm{SD}$ and analyzed by the $t$ test for paired and unpaired groups. In accordance with the rules of our research center, these animal experiments were performed with the highest standards of humane care.

\section{RESULTS}

The baseline blood gases and the hematocrits are shown in Table 1 . These values were all within the physiologic limits, and there were no significant differences between the two groups. During the interval of the maternal hypoxia, the fetal arterial $\mathrm{O}_{2}$ pressure decreased from their baseline values of $2.43 \pm 0.36(\mathrm{kPa}$ $(18.2 \pm 2.7 \mathrm{~mm} \mathrm{Hg})$ to $1.57 \pm 0.17 \mathrm{kPa}(11.8 \pm 1.3 \mathrm{~mm} \mathrm{Hg})$ and returned to baseline values after the recovery period. The $\mathrm{pH}$ values of $7.360 \pm 0.044$ at baseline were $7.331 \pm 0.069$ at the end of the experiment. The globin-chain synthesis profiles of the basal and final states after carboxymethyl cellulose separation are shown in Figure 1. The blood samples were from a fetal lamb that was homozygous for $\beta$-B adult Hb. The percentage of $\gamma$ chain synthesis to the total non- $\alpha$-chain synthesis was $80.1 \%$ at the basal state (135 d of gestation) and $83.1 \%$ at the end of the intermittent hypoxic experiments ( $140 \mathrm{~d}$ of gestation).

The changes in $\gamma$-chain synthesis as a percentage of non- $\alpha$ chain synthesis in both groups of animals at the start and the end of the experimental period are shown in Figure 2. The data from both groups are superimposed on the range of normal sheep fetuses (5). Four of the five hypoxic fetuses did not show a decrease in $\mathrm{HbF}$ synthesis. Table 2 summarizes the changes in $\mathrm{Hb}$ type synthesis obtained in this study. There was no significant difference in the amounts of $\mathrm{HbF}$ synthesis between the controls and the hypoxemic fetuses at the basal state. There was a decrease in the $\mathrm{HbF}$ synthesis in the control group by the end of the experiment $(71.7 \pm 12.1$ to $57.4 \pm 10.2 \%, p<0.001)$. There was no significant difference in $\mathrm{HbF}$ synthesis between the basal and final states in the hypoxic group $(85.1 \pm 11.1$ versus $80.6 \pm$ $18.9 \%$ ), but there was a significant difference between the control group and the hypoxemic group at the end of the experiments

Table 1. Baseline blood gases and hematocrit

\begin{tabular}{lcc}
\hline & $\begin{array}{c}\text { Controls (group II) } \\
(n=5)\end{array}$ & $\begin{array}{c}\text { Hypoxia (group I) } \\
(n=5)\end{array}$ \\
\hline Hematocrit $(\%)^{*}$ & $38.40 \pm 4.16$ & $36.10 \pm 2.66$ \\
$\mathrm{PaO}_{2} \dagger(\mathrm{kPa})$ & $2.55 \pm 0.28$ & $2.43 \pm 0.36$ \\
$\mathrm{PCO}_{2}(\mathrm{kPa})$ & $4.95 \pm 0.25$ & $5.24 \pm 0.16$ \\
$\mathrm{pH}$ & $7.347 \pm 0.022$ & $7.360 \pm 0.044$ \\
\hline
\end{tabular}

* SI unit conversion $\times 0.01$.

$+\mathrm{PaO}_{2}$, arterial $\mathrm{O}_{2}$ pressure.

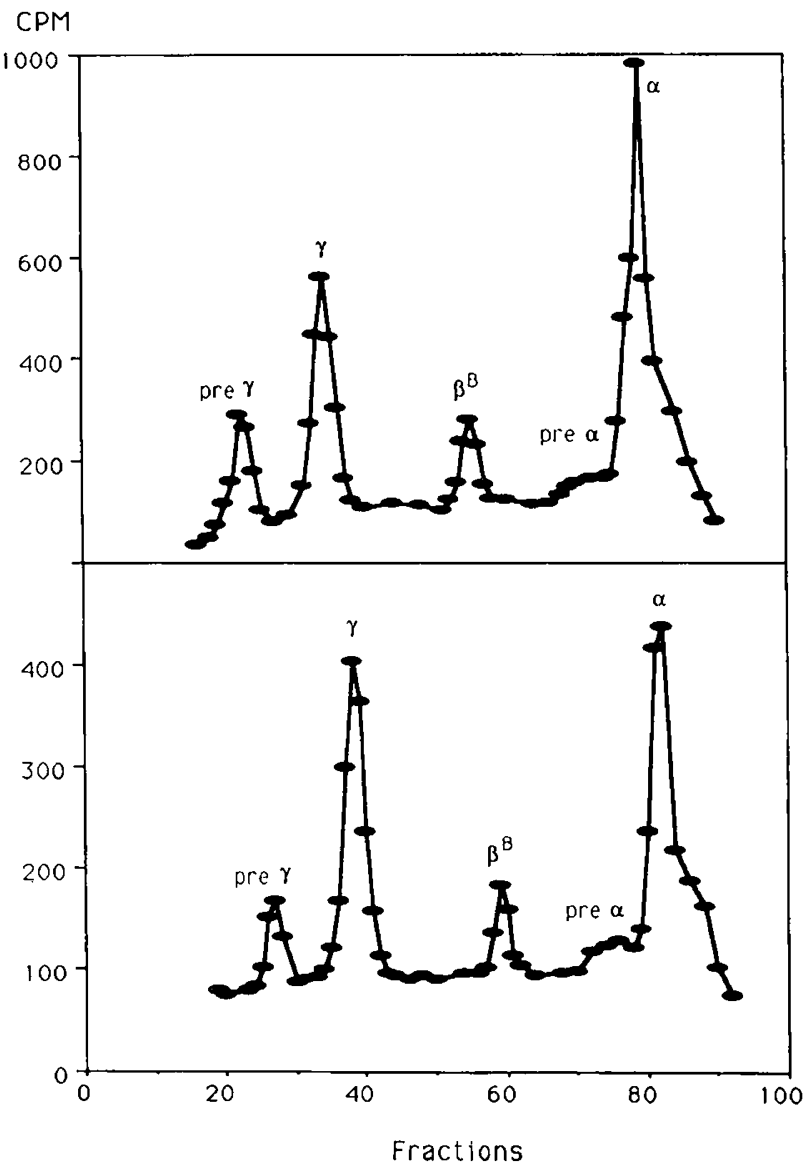

Fig. 1. Carboxylmethyl cellulose chromatography of ${ }^{14} \mathrm{C}$-leucine-labeled globins obtained from a hypoxemic fetal lamb. The HbF synthesis was $80.1 \%$ before the hypoxemic experiments (top) and $83.1 \%$ at the end of the study (bottom).

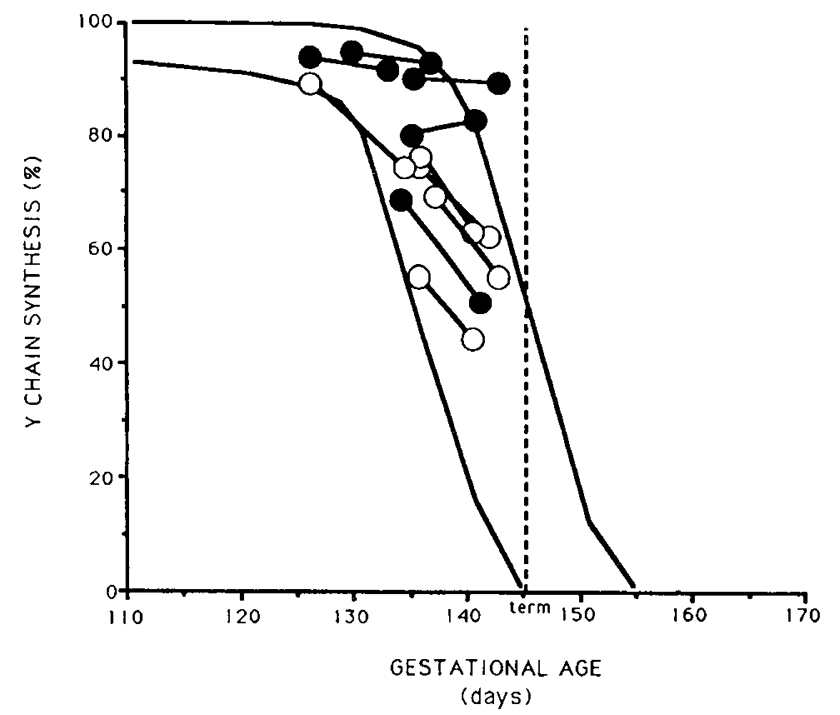

Fig. 2. HbF synthesis as a percentage of total $\mathrm{Hb}$ synthesis in two groups of fetal lambs. $\bullet$, the hypoxemic group; $O$, the control group. The area between the two lines is the normal range of $\mathrm{HbF}$ synthesis from reported data (5).

( $57.4 \pm 10.2$ versus $80.6 \pm 18.9 \%, p<0.05)$. In the two groups, the 2,3-DPG concentrations and $P_{50}$ did not differ significantly from the onset to the end of the experiments, and all of the values obtained remained within the normal range determined in a previous study (7). The values obtained at baseline and at the end of the experiments were $2.2 \pm 0.4$ and $4.2 \pm 1.8 \mu \mathrm{mol} /$ 
Table 2. Comparison of two groups of experiments

\begin{tabular}{|c|c|c|c|c|}
\hline & \multicolumn{2}{|c|}{$\begin{array}{l}\text { Controls (group II) } \\
\quad(n=5)\end{array}$} & \multicolumn{2}{|c|}{$\begin{array}{l}\text { Hypoxia (group I) } \\
\quad(n=5)\end{array}$} \\
\hline & Basal & $\begin{array}{c}\text { End of } \\
\text { experiment }\end{array}$ & Basal & $\begin{array}{c}\text { End of } \\
\text { experiment }\end{array}$ \\
\hline Gestational age (d) & $134.2 \pm 4.7$ & $140.0 \pm 3.4$ & $132.0 \pm 3.9$ & $138.2 \pm 3.9$ \\
\hline HbF synthesis $(\%)$ & $71.7 \pm 12.1$ & $57.4 \pm 10.2^{*}$ & $85.1 \pm 11.1$ & $80.6 \pm 18.9 \dagger$ \\
\hline 2,3-DPG $(\mu \mathrm{mol} / \mathrm{g} \mathrm{Hb})$ & $2.2 \pm 0.4$ & $2.1 \pm 0.1$ & $2.8 \pm 0.4$ & $4.2 \pm 1.8$ \\
\hline
\end{tabular}

$* p<0.001$ compared with basal level in control group.

$\dagger p<0.05$ compared with controls at end of experiment.

$\mathrm{g} \mathrm{Hb}$, respectively, for 2,3-DPG and $2.45 \pm 0.24 \mathrm{kPa}(18.4 \pm 1.8$ $\mathrm{mm} \mathrm{Hg})$ and $2.43 \pm 0.23 \mathrm{kPa}(18.2 \pm 1.7 \mathrm{~mm} \mathrm{Hg})$, respectively, for $\mathrm{P}_{50}$.

\section{DISCUSSION}

The purpose of this study was to determine if increased $\mathrm{HbF}$ synthesis could be stimulated by hypoxemia alone in a stable fetal maternal preparation. The duration of each hypoxic exposure was limited to maintain a stable preparation, yet was long enough for a hypoxemic effect on the erythropoietic system. This hypothesis was based on the time interval required for an increase in serum erythropoietin in both human and animal studies, which showed that after $1.5 \mathrm{~h}$ of hypoxemia in fetal sheep serum erythropoietin levels would be significantly increased $(8,9)$. Increased plasma erythropoietin has been shown to be associated with hypoxemia in fetal sheep (10), and others (11) have demonstrated, by administrating erythropoietin to baboons, that there exists a direct relationship between increases in erythropoietin and an increase in the production of HbF.

An interval of 5 to $6 \mathrm{~d}$ was considered adequate to determine if fetal hypoxemia would have an effect on $\mathrm{HbF}$ synthesis because results obtained using primates, cell cycle-specific drugs, acute bleeding, or recombinant erythropoietin showed that there was an increase in $\mathrm{HbF}$ production within 3-4 d after treatment that peaked at 5-6 d post-treatment (12). There was no significant change in 2,3-DPG or $\mathrm{P}_{50}$ during the study. This lack of an effect of hypoxemia on 2,3-DPG synthesis in the fetal lamb is in agreement with the data described by others (13).

Normally, during the switchover from fetal to adult $\mathrm{Hb}$ synthesis, the proportion of fetal to adult $\mathrm{Hb}$ being produced is dependent upon gestational age. Hypoxemia could possibly have a direct effect on $\gamma$-globin gene expression similar to that described in a study by Perrine et al. (14), in which butyrate infusions in the ovine fetus delayed the fetal to adult globinchain switchover. However, the increased $\mathrm{HbF}$ during the switchover period could also be explained by using the concept suggested by Stamatoyannopoulos et al. (15), which proposes a model relating the pattern of $\mathrm{Hb}$ synthesis to the maturation of the erythroid precursors. Conditions such as hypoxemia result in an increase in erythropoietin that causes a recruitment of immature precursor cells. These immature precursor cells are forced to enter terminal differentiation rather than maturation pathways. The result is that a number of reticulocytes appear in the circulation, producing more $\mathrm{HbF}$ than is expected for the developmental age of the fetus.
This study demonstrates that fetal hypoxemia uncomplicated by other factors can be the cause of levels of $\mathrm{HbF}$ synthesis that are greater than can be expected for the period of gestation. Increased production of $\mathrm{HbF}$ during the perinatal period would be indicative of fetal hypoxemia. This finding could have important clinical significance.

\section{REFERENCES}

1. Bromberg YM, Abrahamov A, Salzberger M 1956 The effect of maternal anoxaemia in the foetal haemoglobin of the newborn. J Obstet Gynaecol Br Emp 63:875-877

2. Bard H, Prosmanne J 1985 Relative rates of fetal hemoglobin and adult hemoglobin synthesis in cord blood of infants of insulin-dependent diabetic mothers. Pediatrics 75:1143-1147

3. Bard H 1974 The effect of placental insufficiency on fetal and adult hemoglobin synthesis. Am J Obstet Gynecol 120:67-72

4. Bard H, Fouron JC 1988 The increase in fetal hemoglobin synthesis in the fetal lamb during hyperglycemic hypoxemia. Am J Obstet Gynecol 159:1269-1272

5. Bard H, Battaglia FC, Makowski EL, Meschia G 1972 The synthesis of fetal and adult hemoglobin in sheep during the perinatal period. Proc Soc Biol Med 139:1148-1150

6. Bard H, Fouron JC, Grothe AM, Soukini MA, Cornet A 1976 The adaptation of the fetal red cells of newborn lambs to extrauterine life: the role of 2,3diphosphoglycerate and adult hemoglobin. Pediatr Res 10:823-825

7. Bard H, Fouron JC, Robillard JE, Cornet A, Soukini MA 1978 Red cell oxygen affinity in fetal sheep: role of 2,3-DPG and adult hemoglobin. J Appl Physiol 45:7-10

8. Cahan C, Hoekj PL, Goldwasser E, Decker MJ, Strohl KP 1990 Assessing the characteristic between length of hypoxic exposure and serum erythropoietin levels. Am J Physiol 258:R1016-R1021

9. Eckardt KU, Boutellier U, Kurtz A, Schopen M, Koller EA, Bauer C 1989 Rate of erythropoietin formation in humans in response to acute hypobaric hypoxia. J Appl Physiol 66:1795-1798

10. Widness JA, Teramo KA, Clemons GK, Garcia JF, Cavalieri RL, Piasecki GJ, Jackson BT, Susa JB, Schwartz R 1986 Temporal response of immunoreactive erythropoietin to acute hypoxemia in fetal sheep. Pediatr Res 20:15-19

11. Al-Khatti A, Veith RW, Papayannopoulou T, Fritsch EF, Goldwasser E, Stamatoyannopoulos G 1987 Stimulation of fetal hemoglobin synthesis by erythropoietin in baboons. N Engl J Med 317:415-420

12. Stamatoyannopoulos G, Veith R, Al-Khatti A, Fritsch EF, Goldwasser E, Papayannopoulou Th 1987 On the induction of fetal hemoglobin in the adult: stress erythropoiesis, cell cycle-specifique drugs and recombinent erythropoietin. In: Stamatoyannopoulos G, Neinhuis AW (eds) Developmental Control of Globin Gene Expression, Alan R Liss, pp 443-453

13. Kitanaka T, Alonso JG, Gilbert RO, Siu BL, Clemons GK, Longo LD 1989 Fetal responses to long-term hypoxemia in sheep. Am J Physiol 256:R2348R2354

14. Perrine SP, Rudolph A, Faller DV, Roman C, Cohen RA, Chen SJ, Kan YW 1988 Butyrate infusions in the ovine fetus delay the biologic clock for globin gene switching. Proc Natl Acad Sci USA 85:8540-8542

15. Stamatoyannopoulos G, Veith R, Galanello R, Papayannopoulou Th 1985 HbF production in stressed erythropoiesis: observations and kinetic models. Ann NY Acad Sci 445:189-197 